\title{
The Innovativeness and The Decision-Making Skills of Primary School Principals
}

\author{
Aceng Muhtaram Mirfani \\ Universitas Pendidikan Indonesia \\ Corresponding e-mail: am_mirfani@upi.edu
}

\begin{abstract}
One of the primary strategic roles of the school principals to drive the school's progressiveness is as a change manager. The school principals have available at the schools as an initiator of innovations and manage it. They have the competence to mapping the school's generic problem that only can to overcome by newer efforts. Therefore the innovativeness and decision-making skills become the core competence of school principals. This article explores the big picture of some primary school principals experience of them and the alternative thinking about how to improve the school principals professionalism. The survey has been conducted on 120 principals of primary school in Bogor Regency. The purpose of the survey was to find out the trend of innovative maps and urgent decisionmaking skills of principals. Methods performed through innovative potential tests and weigh the position of decision-making updates. The findings of the study indicate that the general trend of innovativeness still in the category of early majority and late majority. The tendency of decision-making skills is in a low category.
\end{abstract}

Key Words: Innovativeness, Decision-Making Skills, Change Manager, Self-Propelling Growth

\section{INTRODUCTION}

Just as the role of School Supervisor (Muhtaram: 2015), the principal occupies a strategic position in the effort to improve the quality of school education. The task of the principal performing managerial actions should be able to improve the quality of school management and the task of performing academic supervision to improve the quality of process and learning outcomes. In reality there is a paradox, where the issue of the quality of education is always a national issue of education. Therefore, the optimization of the principal's role becomes more urgent.

The issue of the quality of national education is still prominent because what has been achieved has not met expectations. Even the efforts to meet the eight national standards of education are often constrained. Efforts to implement school accreditation, as an indicator of improving the quality of educational units, over the last two years (2013 and 2014) are reported to be unable to achieve established targets and even significant reductions. In the Government Institution Performance
Accountability Report (LAKIP) Ministry of Education and Culture for year 2014 shown as in the following table:

Table 1. Level of achievement of education quality standard

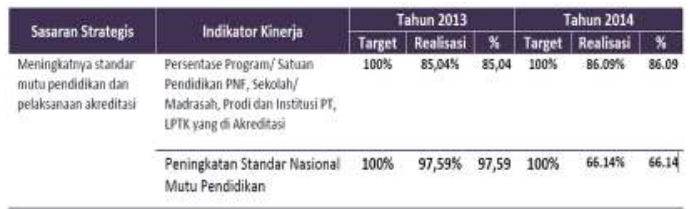

Source: The Government Institution Performance Accountability Report of MoEC 2014, page 80.

It appears in the table above that there is a decrease in the percentage of achievement of the target of increasing the quality standard of education and the implementation of accreditation from $97.59 \%$ in 2013 to $66.14 \%$ in 2014. One of the causes of non-target achievement is reported because the target setting in the strategic planning is too high. Although in "LAKIP" 2015 presented with different formats, the realization would be comparable with the previous year. In the data, 
several things indicate a decrease, especially related to the achievement of quality indicators at the Primary level (SD / SDLB and SMP / SMPLB). It can thus be observed on the data as follows:

Table 2. The achievement of performance indicators to improve the quality of services and graduates

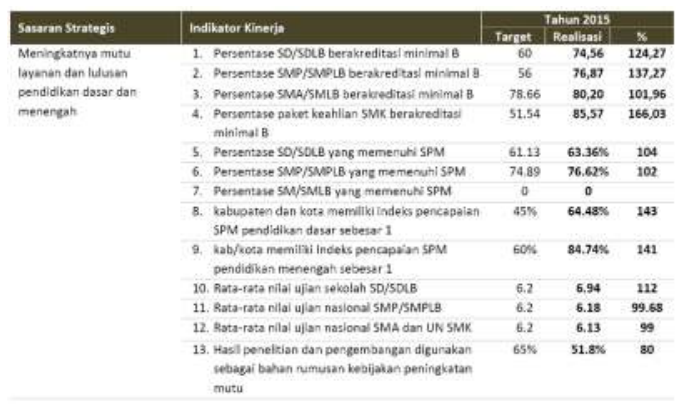

Source: The Government Institution Performance Accountability Report of MoEC 2015, page 58.

Behind the information on the "LAKIP" of MoEC above, it can be assumed that the performance of most principals is still problematic. In relation to the improvement of school education quality, the problem concerns the ability to manage change in schools. To be a successful change manager depends entirely on innovation and urgent decision-making skills. Thus both of these are the basic capital for the principals to be able to advance education in school.

\subsection{Challenge of Change in School}

Among the challenges that can greatly affect the progress of an organization is the progress of development of information and communication technology. The rapid development of information and communications technology (ICT) is strengthening and even becoming a proof of the realization of a world borderless. Furthermore, ICT in the midst of globalization has brought fundamental implications by shifting the value of products and services from the physical to digital realm. Toffler (1990) describes (in "Power-shift") that we are in an era of globalization which, among other things, is characterized by a "super symbolic" culture. Transaction tools that originally form objects (paper or metal, money) can be replaced by a new symbol that is in the form of electronic money. The essence is information packed in a digital facility.

In relation to these changes, organizational experts divide the three main features of the special role of leaders (Kanter: 1983). First, imagination to new things. To encourage innovation, effective leaders help develop concepts that define different organizations. Second, professionalism to perform. Leaders provide organizational and personal competencies, supported by training and development workforce, to execute perfectly and deliver more value than customers demand. Third, open to collaboration Leaders connect with partners who can expand the reach of the organization, improve their presentation, or add to their work habits.

Thus there is no longer any organization that can be immune to change, including school-type educational organizations. According Kanervio \& Risku (Jukka Alava Cs. 2012) can also be assumed that the chain of change will happen continuously and become more intense. It therefore becomes more important how to keep the principals constantly innovating 'themselves'. For if it only implements externally enforced changes according to Tony Bush (2017) they tend to do so without the enthusiasm that causes failure. Of the many organizations that have attempted to respond by also making changes to the reality, not many are successful in a resounding manner (Kotter: 1998). According to the results of his studies there are many mistakes have been made by the leaders of these organizations. A lot of learning thereof for organizational change in the future. In this connection, eight steps are suggested for organizational change which can be summarized as follows:

- Creating a sense of urgency: Checking and competitive realities; Identify and discuss crisis, potential crisis, or key opportunities.

- Establish a strong coalition to guide: Group one group with sufficient strength to lead change efforts; Encourage the group to work as a team 
- Make a vision: Create a vision to help direct the change effort; Develop a strategy to achieve the vision

- Communicating the vision: Use every possible vehicle to communicate new vision and strategy; Teach new behavior with examples of coalition instructions

- Empower others to act on a vision: Get rid of the constraints to change; Changing a system or structure that seriously destroys vision; Encourage risk taking and non-conventional ideas, activities, and actions.

- Make plans to win in the short term: Plan real performance improvements; Create improvements; Recognize and respect the employees involved in the improvement.

- Consolidate improvements and make more changes: Use increased credibility to change systems, structures, and policies that do not fit the vision; Raise, promote, and develop employees who can implement the vision; Revive the processes with new projects, themes, and change agents.

- Institutionalize a new approach: Articulate the relationship between new behaviors and organizational success; Develop ways to ensure succession and leadership development.

Why an organization broke up. Among the most appropriate answers, because the problems that occur-that determine the futureare left unsolved. This means that no correct visionary decision is made. The issues that determine the future of the organization are more related to the demands of environmental development. Because it involves the ability to make adjustments or changes. Thus decision making in the concept of survival (survive) with respect to the decisions of innovation (Muhtaram: 2012). In line with the initial step to make organizational change according to
Kotter, then the decisions of innovation is also an urgent decision.

Organizations can be able to survive when innovative decisions are made in line with the demands of development and environmental progress. The absence of overcoming the visionary problems faced or the innovations is not decided, thus resulting in the organization in an entropy state that leads to the disorganization or death of the organization. Similarly, educational units such as schools that are not able to make adjustments in line with the demands of development and strategic environmental progress where the aspirations of stake-holders usually depart from it. Gradually the education unit was soon abandoned because the stake-holders no longer appreciated the outcomes that their graduates might have gained. Not a few educational units that are just labeled, no longer operational because they do not have a sufficient number of learners. It is very likely that the main cause of decision-making to address visionary problems is not working. No urgent decision was made. The stronger meaning is that the principal must be present as a problem solver, as well as an innovator. The principal must be present as a manager of change, even more ideal as a master of change. Basic skills that must be mastered as a qualities of a change master (www.citehr.c0m / 70652-qulities-change master) include:

- Common sense. And the courage to use it.

- Credibility and trust - the ability to work at all levels in the organization.

- A wide range of business knowledge - preferably someone with experience in 3-4 different areas, or an MBA, or a general management experience.

- Knowledge of change management.

- The ability to work with teams of people both inside and outside the organization.

- This includes the ability to work with people across all departments.

- The ability to do very unstructured work. 
- Creativity. The ability to custom design processes to meet the goals of the organisation.

- Self confidence balanced by humility.

- Facilitation skills, Design skills, Coaching skills.

- A love of innovation and new ways of doing things.

- A sense of humour and a sense of fun.

- A spirit of caring.

- The ability to inspire people. To bring out the magic within every individual and every team.

The innovation is defined by Everett M. Rogers (1983: 22) as "the degree to which an individual or other unit of adoption is embraced earlier in adopting new ideas of the other members of a system". He further categorizes five types of adopters, namely (1) innovator: venturesome, (2) early adopters: respectable, (3) early majority: deliberate (4) Late Skeptical, and (5) traditional laggards. Furthermore, each category was introduced as innovator, pioneer, follower firts, follow then, and left behind.

\subsection{Case Study Of Keinovatives And Skills Making Decision Of The Head Of School}

\section{Study Design}

A simple study has been conducted on a number of principals with a view to:

- Mapping the principal's innovation

- Identify the principal's decisionmaking skills to initiate a renewal effort at school

The questions asked are:

- How to map the innovations of the principals?

- What is the tendency of urgent decision-making skills for principals?

Methods and procedures taken are to test the potential for innovation and test potential weigh the position of decision making updates. To prepare the instrument as follows:

Innovative Test Instruments include:

- 10 items of statement adopted 4 (each weighing 5, 10, 15, 20 designed based on Rogers theory categorization)

- Pattern of calculation by criteria: (180200 as innovator, $145-175$ as pioneer, $110-140$ as follower first, $75-105$ as follower then, and 40-10 as left behind)

The Decision Making Test Instrument includes:

- C. Theoretical mastery for decision making (scale 5)

- D. Mastery of regulation for decision making (Scale 5)

- E. Mastering the problem-solving thinking framework for updates (Scale 5)

- F. Intensity of experience making urgent decisions (Scale 3)

As a sample study was taken 120 principals of primary school in Bogor regency.

\section{Study Results}

\section{Map of The Principals Innovativeness}

The results of data analysis from innovation test resulted in the principal's innovative map as depicted in the following chart:

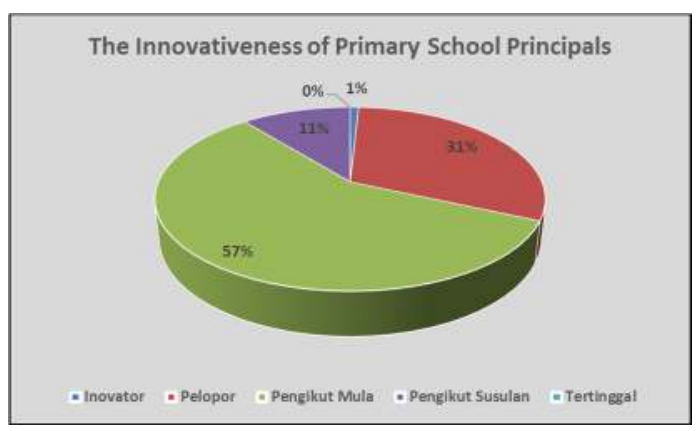

Figure 1. The Innovativeness of Primary School Principals 
From a sample of 120 principals in the case study in Bogor regency, there is no category left behind and only about $11 \%$ are categorized as follower then. As the follower first categories are about $57 \%$ and most are $31 \%$ categorized as pioneers. The principal categorized as innovator is only about $1 \%$.

\section{Trend of Decision-Making Skills of Elementary Principals}

In relation to the role of principal as a manager of change in the potential of making urgent decisions tested on three skills indicators, namely the mastery of theoretical concepts, the mastery of regulative knowledge, and the mastery of problem-solving frameworks that demand change. The results of data analysis of decision-making skills test resulted in the distribution of skill-making skills of principals as illustrated in the following diagram:

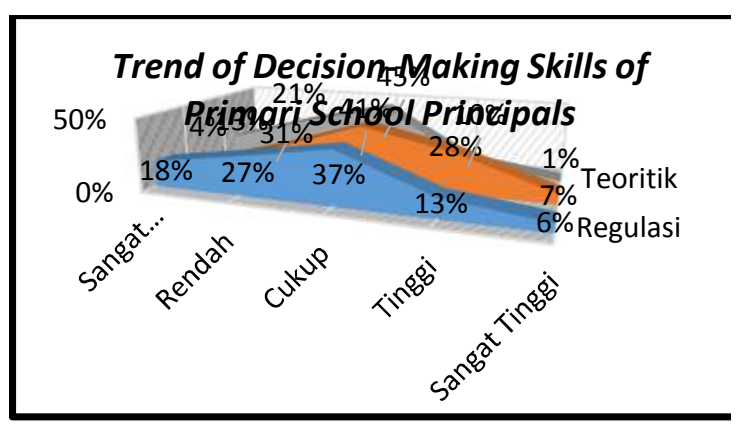

Figure 2. Trend of Decision-Making Skills of Primary School Principals

From a sample of 120 pincipals, there was a tendency in terms of theoretical mastery of decision-making, ie almost half (about 45\%) were in sufficient position, only $10 \%$ were in high positions and $1 \%$ at very high positions, Even about $21 \%$ at low positions, and about $13 \%$ at very low positions.

In terms of mastery framework recognizable trend, which is about $41 \%$ are in position enough and $10 \%$ in high positions, even only $1 \%$ in very high positions. At low positions there are about $31 \%$ and at very low positions around $4 \%$.

The regulatory mastery of decision making is recognized by tendency, which is only $6 \%$ in very high positions and $13 \%$ in high positions. In a sufficient position there are $37 \%$ and low position there is $27 \%$. The rest is about $18 \%$ at very low position.

In addition to the recognition of the tendency of the above-mentioned decisionmaking skills, it is also recognizable the tendency of the intensity of urgent decisionmaking over the past year. The results of data analysis on the intensity of urgent decision making yielded information on the tendency of urgent decision-making intensity of principals as illustrated in the following chart:

\section{Trend of Urgent Decision-Making Intensity} by Primary School Principals

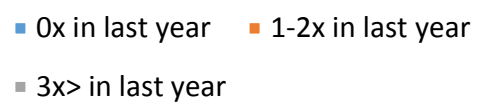

- $0 x$ in last year $\quad-1-2 x$ in last year

$=3 x>$ in last year

Figure 3. Trend of Urgent Decision-Making Intensity by School Principals

The level of intensity of urgent decision making over the past year is divided into three categories, ie the category never makes urgent or 0 decisions, the categories make urgent decisions one to two times, and the categories make urgent decisions three times more.

In fact, more than half of the heads (about $52 \%)$ have never made urgent decisions and only about $12 \%$ make urgent decisions one to two times over the past year. As for who make urgent decisions three times more in a year there are about $36 \%$.

\section{DISCUSSION}

Based on the results of the study as discussed above, at least discussions can be carried out in two focuses, namely the correlation of education quality improvement in schools with innovative tendencies and principal decision-making skills and on alternative breakthroughs of principals' empowerment in educational reform efforts. The first focus is a discussion of the reinforcement of the fundamental issues of stagnant reform in schools and the second focus is a discussion of alternative search thinking solutions. 
Focus-1 Problems of Improving the Quality of Education in Schools with Innovative Trends and Principal Decision-Making Skills

As basic assumptions have been put forward since the beginning of this paper, the improvement of the quality of education in schools is also the main target of the presence of school principals, so inherent in the requirements of a principal is important to note in the effort to improve the quality of education. Moreover, innovation and urgent decisionmaking skills are closely related to managing change. Is not quality improvement impossible without change. It departs from defining change as a difference from the initial state compared to the next state (terminal state). In the context of change management, the difference refers to better condition which is indicated by positive growth or development or said improvement (Muhtaram: 2009).

Of course the innovation that must be attached to the principals is at least in the pioneer (early majority) category because they must be able to bring all their members of school community to run the innovation. He is a change agent at school. It would be ideal if the principal's innovation could be in the innovator category, so that he could attend as a master of change. Literally according to Kanter (1983: 306) that the master of change is: "the right people, in the right place at the right time". In that case the principals in general have not been able to attend, so the progress of schools, including improving the quality of education in schools can not be maximized. Indeed as an innovator according to Rogers (1983: 248) they "very eager to try new ideas. This interest leads them out of a local circle of peer networks and into more cosmopolite social relationships ". In line with that also Kanter (1983: 305) asserted that the tool for master change is "creative and interactive; They have an intellectual, a conceptual, and a cultural aspect ".

Similarly, the skill of making urgent decisions that generally still shows a tendency that only a small part is at a very high ability. In line with Kotter (1998) on a critical step, the existence of a "sense of urgency" on the principals that in general still does not exist. In the past year there were about $17 \%$ of principals never making urgent decisions. That's why renewal efforts in schools have not yet flourished. Even if a small proportion (18\%) of the principal has made three or more urgent decisions, it seems that they have not been able to boost the reform effort at school. It may be that Rogers (1983: 248) "the innovator plays a gatekeeping role in the flow of new ideas into a social system" has not been fully actualized by the headmasters of such a minority.

Focus-2 Alternative School Principal

Strengthening in Education Renewal Efforts

The strengthening of school principals in the effort to accelerate school progress is basically a combination of two basic strategies of empowering, and energizing the grass root (Muhtaram: 2009). Change strategy experts see that empowerment is a very powerful strategy. This strategy philosophy is based on the view that change is essentially changing human beings with all its aspects - intellectual, mental, and spiritual. Changes are only possible if the human is changed. So the actors change is human. Every human being has the power to change himself, change all aspects of humanity, change his life and change his environment.

The philosophy underlies empowerment. Humans as actors of change are given the power to change themselves, life, and environment so that they can be different and ready as agents of change. Ready to act in change. Transforming people with their mindset, attitude patterns, and patterns of behavior. In accordance with Kanter (1983) that in the context of most changes there are four components of empowerment, namely: power tools, open communication, network forming devices, and dissemination of resources decentralization of resources.

Its application of power or power tools is implanted into each principal so that the energy it possesses becomes an intelligent person. The power tool consists of information, resources, and support. Information as a tool of strength includes, among others: data, technical knowledge, political intelligence, and expertise in school headship. Resources as a tool of strength include: funds, materials, space, and time. While support can be endorsement, backing, approval, and legitimacy of school headship.

Changes need to be complemented by open communication. How to prevent change in the process and control of barriers to deliver messages, such as blocked by bureaucratic flow. In this connection the flexibility of 
communication is an important element for potential entrepreneurs. With the flexibility of policy communication and creativity innovate on the principals will be facilitated.

The networking apparatus is a guarantee of peer support among principals. Because the change concerns many people, there must be a connecting hand that spreads to different lines and corners. Just as the nerves are the connective tissue of the body parts to one another. This interface should touch strategic points to the agent and change targets. The connectedness of the established principals' tasks must be well preserved because change is not possible without interconnection.

With the implementation of the four tools of empowerment component as mentioned above, the change effort at school has a chance to succeed. Because with it means empowerment touches the core of managing change. In this case empowerment makes the headmaster "well-informed" (ie, those who have no shortage of material because they are knowledgeable). They always learn and continue to learn independently (self-propelling growth).

Grassroots strengthening means empowering principals who are seen as common people. This strategy philosophy starts from some basic assumptions. First, that change affects the livelihood of the people and therefore they must be empowered to contribute to change. If change is to succeed people who accept change must be empowered because change touches their life.

Related to that that for the headmaster can change themselves then there must be readiness to accept change (readiness to accept change), which among other things by opening up (openness) to change. Added to the principal's power is a wider insight, the excitement of new challenges and greater opportunities. With such power they seem to be more alive.

The basic strategy aimed at broader interests, organizational systems, among others, as the model put forward by Bennis (1975). There are four strategies that can be done in order to change more broadly. The four strategies are rational-empiric, normative-reeducative, power-coercive, and environmentadaptive.

\section{RECOMMENDATION}

Starting from the basic and broad strategies mentioned above, as an alternative thought is also proposed four breakthrough strategies for strengthening the principal as a recommendation.

\subsection{Give Principal Freedom to Act}

Freedom to act philosophically is the foundation of a climate that is conducive to the flourishing of creativity among principals. Freedom to act should be interpreted as providing creative opportunities based on the professional responsibility of heads of schools. Creative action by any person should have a logical basis or logical reason that is professionally acceptable. Thus, innovations can be present to support change efforts in schools.

That human capacity to discover and create is universal (Wheatley: 2001). The problem is how do we know that the people within our organization have the potential to innovate? And how do we inflict on them that they need and need to innovate. That it should be understood that people and organizations as living systems, filled with innovative dynamical characteristics of all life, many of the problems that survive have become soluble. Perhaps the most powerful in this example is how the job is relatively easy to make the organization successful.

\subsection{Give the Principal a Wider Power}

How the principals continue to keep change optimally and continue to initiate and carry on the next change, when he makes sure it's time for more change. We remember back to the exposure of the change cycle upfront. Among the necessary for this is not only the principal can freely innovate, but also important, especially for lower-level leadership groups or special teams, is a protection that he has the authority for the task of change in school.

According to organizational theory and principle, the structure of position and duty is inherent in its authority. But in the context of change management, positions at any level 
need assertion of broad authority in managing change. So that for the headmaster may get support doubled from the people around him. It is important to distinguish between hierarchical relationships, superiors, and collegial relationships. With regard to formal tasks that have been standardized regular arranged obligations and responsibilities. Hierarchically means building a superior-subordinate relationship. For the duties of organizational change, it is often more demanding to build links to collegiality. It is closely related to the indicators of creating appetite for change which is one of the properties of organizational intelligence (Albrecht: 2003).

\subsection{Supporting Various Parties Associated with Schools}

Of all the challenges associated with the team of a change effort in school, the biggest one is involving their own people. The effectiveness of a team depends on many things that include harmonization, attitudes, motivational sources.

The real achievement of group collaboration depends on three stages (Forsberg, Kevin:

2005):

- Forming a group capable of being a team,

- Create and maintain a cooperative environment of a group, and

- Awaken the spirit of successful teamwork through leadership.

\subsection{Develop a Quality Culture in School}

Returning to the meaning of change for improvement and associated with the purpose of school survival where changes are made, this means that change is also placed in the culture of competition. Schools need to have strong competitiveness. For in this case change not only just to exist, but further how to lead in the dynamics of change. So principals do not simply change for adaptation to change, but also create change.
Schools that are capable of creating change are the ones that make the environment more dependent on them. He will be difficult dammed when intervening on his competitors. Such a reality we can see how powerful companies or countries can control for others who are adjusting to their policies.

As for which is a key supporting factor for the change in the direction mentioned above is a superior culture that penetrated in all lines of organization. Superior in this case is able to go beyond the existing ones. Not satisfied just what has been achieved. This embodiment of "today is the same as yesterday is loss, let alone worse is woe".

In line with that interest Paul Stoltz (2000) after researching about 25 years and successfully identifying the barriers of people to achieve their ultimate success. From his findings he succeeded in formulating one's resilience formula in responding to adversity that was later introduced as "Adversity Quotient". An assessment with ARP (Adversity Response Profile ${ }^{\circledR}$ ) a shows us where we are resolute in the face of adversity and where we are not. It explains why we might stagnate, or quit when getting difficult things. For then in combination with other personal lives or other successes, ARP results can help us significantly to improve our AQ and smoothness in core skills. We can increase optimism and excitement. We also increase our capacity to make things superior to us.

\section{CONCLUSION}

1. In general, the principal has not been able to carry out renewal tasks to improve the quality of education in schools.

2. The innovation of the principal shows an inadequate tendency to role as an agent let alone as a master of change.

3. The principal's skill in urgent decision making generally still shows the lack of conditions to encourage the growth of educational reform at school.

4. There is still hope in strengthening the role of principals to initiate and control the implementation of renewal in schools through the breakthrough of application of 
alternative strategies based on selfpropelling growth.

\section{ACKNOWLEDGEMENT}

I would like to express my sincere gratitude to the Bogor District Personnel, Education, and Training Agency for the support that has been given to conduct the survey in this research.

\section{REFERENCES}

[1] Alava, Jukka; Halttunen, Leena \& Risku, Mika (201). Changing School Management; Finland-Finnish National Board of Education and authors.

[2] Albrecht, Karl (2003). The Power of Minds At Work: Organizational Intelligence in Action; American Management Association.

[3] Bennis, Warren G.dkk. (1974). The Planning of Change, 2nd Edition, New York: Holt, Rinehart and Winston Inc.

[4] Bush, Tony (2007). Educational leadership and management: theory, policy, and practice, South African Journal of Education Copyright; EASA 27, 3, pp. 391406.

[5] Dembowski, Frederick (2006). The Changing Roles of Leadership and Management in Educational Administration; International Journal of Educational Leadership Preparation, 1, 1 , (January - June, 2006).
[6] Forsberg, Kevin (2005). Visualizing Project Management: models and frameworks for mastering complex systems; by John Wiley \& Sons, Inc.

[7] Fullan, M. (2007). The New Meaning of Educational Change. New York: Teacher College Press

[8] Kanter, Rosabeth Moss (1983). The Change Masters, Corrporate Entrepreneurs at Woark; London, George Allen and Unwin.

[9] Kotter, John P. (1998). "Winning at Change" Leader to Leader. 10 (Fall 1998)

[10]LAKIP Kemendikbud tahun 2014. Kemendikbud 2014.

[11] Muhtaram, Aceng M. (2009), Manajemen Perubahan: Landasan Teoritis Untuk Praktik Kepemimpinan Institusional Pendidikan; PT Sarana Panca Karya Nusa, Bandung.Muhataram, Aceng M. (2012). Modul Pemecahan Masalah dan Pembuatan Keputusan, Badan Diklat Kabupaten Bogor.

[12]Rogers, Everett M. (1983). Diffusion of Innovations, third Edition, New York: Macmillan Publishing Co., Inc.

[13] Toffler, Alvin (1990). Powershift; Knowledge, Wealth and Violence at the Edge of the 21st Century; Bantam Books.

[14] Stoltz, Paul (2001). Adversity Quotient@Work ; Morrow, New York, 2000.

[15] Wheatley, Margaret J. (2001). Innovation Means Relying on Everyone's Creativity

[16] www.citehr.c0m/70652-qulities-change master Quality of Change Master. 